\title{
Empreendedores culturais imigrantes em São Paulo de 1950
}

Maria Arminda do Nascimento Arruda

A cidade de São Paulo, nos anos de 1950, passava por modificações ponderáveis em todos os planos da convivência urbana e adquiria os contornos definitivos de metrópole, substrato do aparecimento das instituições da cultura e das novas linguagens ${ }^{1}$. D esde o pós-guerra, as grandes cidades mundiais estavam submetidas a processos de redefinição das funções urbanas, de readequação da malha ocupacional do espaço, visível na tendência à desconcentração dos bai rros étnicos, na reestruturação das relações inter e intrametropolitanas (cf. Gottdiener, 1997, p. 25). No meio do século, a capital paulistana perdera 0 ar acanhado dos anos que viram nascer o M odernismo, momento no qual os imigrantes, concentrados em bairros preferenciais, representavam um terço da população, conferindo um tom estrangeirado à cidade. Alterava-se o ritmo da vida urbana e a antiga cidade, moldada na dinâmica da economia cafeeira, apresentava-se com renovado layout, pontilhado pelas chaminés.

A economia paulista ancorava-se em condições extremamente favoráveis para seu pleno desenvolvimento, com a poderosa ampliação de sua capacidade de acumulação por meio da integração das atividades cafeeiras, da agricultura variada, da rede introvertida dos transportes, da diversificação do pequeno comércio varejista ao grande atacado, do sistema bancário e, sobretudo, da potencialidade revelada no setor industrial ${ }^{2}$. N esse processo não interrompido, os anos de 1950 são herdeiros da década anterior. Foi
1. “Acelera-se, também, no nível do espaço urbano construído com a entrada do capital estrangeiro, especialmente no governo JK, mas que tem seus anseios plantados muito antes, com os 'revolucionários' gritos de modernidade exigidos pela Semana de 22" (Souza, 1994, p. 25).

2. Apesar de não ter mais a hegemonia quase absoluta em termos de sua importância na pauta de exportação, 0 café continua a ter participação expressiva no desempenho da economia, já agora alicerçado deforma cada vez mais intensa pelo setor indus 
trial (cf. Cano, 1977, p. 257; 1985, cap. 3).

3.0 número de operáriosempregados no estado de São Paulo passou de 488.633 em 1950 para 647.244 em 1960 (cf. Pereira, 1967, p. 31).

4.Entre 1944 e 1955 as indústrias debens de capital aumentaram sua produção em 892\%, ao passo que 0 setor de bens de consumo cresceu apenas 196\% (cf. Pereira, 1967, p. 29).

5. Assim mesmo, a relação entre a produção de bens de consumo e de bens de produção tinhasido sensivelmentealterada. Considerando-se apenas os cinco ramos mais importantes no primeiro setor, e seis no segundo, no período de1949 a1959, bens deconsumo reduzem sua participação de $47,3 \%$ para $34,9 \%$, enquanto bens de produção elevam de $34,9 \%$ para $42,7 \%$ (cf. Singer, 1974, p. 59). nesse período que nasceu mais da metade de todas as indústrias mecânicas, um terço das metalúrgicas e um quarto dos estabelecimentos destinados à produção dematerial elétrico e de comunicação, em relação ao parque existente em 1958. 0 desenvolvimento de estabelecimentos industriais destinados à produção de material de transporte e de autopeças, junto com o processo de intensa modernização por que passa a indústria alimentícia, completam o quadro de diferenciação industrial alcançada nesta fase (cf. Pereira, 1967, p. 29). Em decorrência disso, e como resultado da ampliação da massa salarial distribuída, os bens de consumo dos assalariados tiveram um incremento, trazendo à cena do mercado atores até então ausentes. 0 dinamismo do setor industrial mobilizou trabalhadores antes envolvidos em atividades primárias, ao mesmo tempo em que arrastou significativas parcelas da população rural, pelo aumento das rendas agrárias atreladas ao elã urbano ${ }^{3}$.

Se no período que vai de 1950 a 1958 reduziu-se a ampliação física do parque industrial, houve, em compensação, a intensificação dos investimentos, numa transformação qualitativa que torna a década um dos momentos cruciais da industrialização de São Paulo. N esse decênio, os setores de material elétrico, de comunicação e de transporte, que exigiam matériaprima específica, capitais e tecnologia avançada, e mão-de-obra qualificada, caracterizam a instalação do setor de bens de capital ou bens de consumo duráveis, marcando o início de uma nova fase no processo de industrialização da cidade, em que esses setores assumiram a liderança do ritmo de crescimento, vis-à-vis ao setor de bens de consumo ${ }^{4}$. N os meados dos anos de 1950, muda o padrão de industrialização e, portanto, do próprio processo de desenvolvimento do capitalismo no Brasil. Abandonamos a fase da industrialização restringida, que vai de 1933 a 1955, e ingressamos na da industrialização pesada, que durará de 1956 a 1964, conforme a periodização clássica de João M anuel Cardoso de M ello (1982).

São Paulo transformava-se no centro manufatureiro hegemônico do país. A concentração regional era indispensável às economias de escala, que requeriam o investimento em técnicas modernas, ensejando o aumento da produtividade. Em 1950, o sonho acal entado da industrialização que alçaria o país ao mundo dos países desenvolvidos parecia viável e próximo. A indústria, particularmente aquela instalada em São Paulo, tornava o país auto-suficiente em produtos perecíveis e semiduráveis de consumo ${ }^{5}$. A produção doméstica de bens ou insumos, antes importados, intensificouse: bens de consumo duráveis, como automóveis e eletrodomésticos; bens 
de capital, máquinas e equipamentos; e bens intermediários, siderúrgicos, químicos, borracha, papel (cf. Singer, 1983, p. 124). A notável expansão do setor produtivo industrial atraiu o interesse das empresas estrangeiras, que passaram a trocar suas antigas agências comerciais por filiais envolvidas em atividades manufatureiras. As facilidades oferecidas pelo governo brasileiro para a entrada de capital estrangeiro, exigindo apenas a sociedadecom brasileiros ou a compra de suas empresas, aceleraram o processo. 0 impacto dessas iniciativas não se fez esperar. Se em 1950 a indústria brasileira era formada por um grande número de empresas nacionais e privadas, cuja propriedade pertencia geralmente a uma mesma família, em 1960 metade do capital industrial em São Paulo estava sob domínio estrangeiro, com exceção das oficinas de artesãos. As conseqüências avassal adoras da desnacionalização do parque industrial eram em parte compensadas pela introdução de métodos modernos de distribuição e financiamento das operações ${ }^{6}$.

Sob a égide do capital estrangeiro, os novos ramos industriais já surgiam altamente concentrados, agregando-se ao município paulista ou circunvizinhos num fenômeno de cornubação dos mais intensos já verificados na história ocidental. D elineia-se, de pronto, uma Grande São Paulo em que não se vê solução de continuidade espacial entre a extensa urbe e seus saté lites, municípios como Santo André, São Bernardo, São Caetano, GuaruIhos, Caieiras, Diadema, Embu, Ferraz de Vasconcelos, Itaquaquecetuba, Franco da Rocha, O sasco, M auá, Poá, Suzano, Barueri eTaboão da Serra?.

H orizontal ização e verticalização foram processos simultâneos na grande metrópole nos anos de 1950. Se a concentração das atividades constituiu-se em condição favorável ao desenvolvimento econômico, foi ao mesmo tempo matriz geradora de incontáveis problemas de sobrevivência urbana. Sem planejamento, ou com planejamento tardio e parcial, o vocabulário nada plástico das dificuldades logo se ampliou: inadequação do sistema de esgotos, que polui os rios; carência de água potável trazida de longas distâncias; adensamento do tráfego urbano pela precariedade do transporte coletivo; vias insuficientes para o excesso de véculos. Em suma, problemas que denunciam a metrópole moderna, ainda que sob o jugo de condições periféricas.

A metrópole moderna podia ser entrevista na pluralidade das atividades realizadas. Para além da indústria, o comércio e as finanças ingurgitaram 0 setor terciário; a rede de ensino e o número dos cursos profissionalizantes cresciam; os serviços pessoais, com o surgimento de estabelecimentos de luxo, como hotéis, restaurantes, bares, salões de beleza, clubes, saunas,
6. A reação dos empre sários nacionais à penetração do capital estrangeiro variou da simples irritação pela competitividade que se passava a exigir deles à adesão, comprazendo-se em receber os novos investimentos (cf. D ean, 1971, p. 252).

7. Em 1959, a contribuição da Grande São Paulo parao produto industrial era de $70 \%$ (cf. Singer, 1974, p. 60).

8. Joseph Lovedistingue três fases no desenvolvimento urbano deSão Paulo: prémetropolitana (1875-1915); metropolitana inicial (19151940); metropolitanização (a partir de 1940). D estaca que na primeirafase, jáno século XX, São Paulo concebeu um razoável programa de saúde pública, escudado em gastosper capita equivalentesaosaplicadosnos EstadosUnidosno mesmo período. Em 1920, maisdemetadedos 120 municípios paulistas possuíam algum tipo de sistema de esgotos e todos tinham um serviço público defornecimento de água (cf. Love, 1982, p. 120). 
9. 0 crescimento populacional deSão Paulo é intenso no período. Em 1920, a cidade tinha apenas 580 mil habitantes, um terço dos quais estrangeiros. Em 1950, alcançara 2.200.000 e, apenas quatro anos depois, em 1954, atingiu 2.820.000 (cf. Araújo, 1958, p. 169). escolas de judô, de ioga, desenvolviam-se, além da prestação de serviços domésticos, como empregadas, motoristas e outros mais. D ois outros indicadores são sintomáticos, ainda, da metropolitanização: a força de trabaIho empregada no setor de serviços, que passou de 50\% em 1940 para $60 \%$ em 1950, e o número de desempregados na Grande São Paulo, que em 1953 era de 10\% entre os homens e 5\% entre as mulheres (cf. Singer, 1983, pp. 124 e 127).

São Paulo é, já na década de 1950, uma cidade com perfil cosmopolita e moderno, onde se produz "um ponto de inflexão na trajetória das relações entre a metrópole e o urbanismo, que assumia uma nova versão, a de planejamento urbano" (M eyer, 1991, p. 5). O s seres sociais que a habitam explicitam o que de mais exótico pode haver numa sociedade em processo de modernização abaixo do equador, formada a partir de um complexo mosaico de agregações étnicas, raciais e culturais. Parte substancial do denso repertório de linguagens culturais urdidas em São Paulo nos anos de 1950 deve-se, sem dúvida, ao caldeamento populacional e, muito especialmente, ao poderoso fluxo migratório. As populações indígenas e negras foram perdendo sua superioridade numérica em favor daquelas recémchegadas, fossem imigrantes ou migrantes do meio século. No período áureo da imigração, entre 1882 e 1930, 2.223.000 pessoas chegaram a São Paulo, correspondendo a aproximadamente $18 \%$ da população total do estado. O s italianos eram a grande maioria desse contingente, aproximadamente 1 milhão, cerca de $50 \%$ do total; na torrente dos povos peninsulares, portugueses e espanhóis representavam, cada um deles, 18\%, o que equivale dizer que mais de $80 \%$ dos imigrantes procediam da Europa latina, seguidos em menor escala por japoneses, sírios, libaneses, poloneses, judeus, armênios e alemães (cf. Love, 1982, p. 28)9.

Pode-se imaginar a babel cultural resultante desse impacto étnico elingüístico, pois ao mesmo tempo em que se sobrepunham e se miscigenavam, os imigrantes preservavam o cultivo de suas tradições ancestrais nos seus redutos espaciais: os bairros de imigrantes. Apesar da redução das correntes imigratórias nos fins dos anos de 1930, em especial a partir das restrições impostas pela legislação de 1934, foi exatamente na década de 1950 que sua presença se impôs. O simigrantes e sobretudo a primeira geração de descendentes aqui nascidos começaram a alcançar o topo da escala social em múltiplas atividades, das primárias às terciárias, com presença crescente nos meios de comunicação social, nos aparelhos culturais, na literatura, no cinema, no teatro, explodindo uma gramática cultural variegada, de múlti- 
plos tons, densamente impregnada pela nova sensibilidade. E não importava que o fluxo imigratório tivesse arrefecido ou que muitos deles tivessem apenasfeito escala em São Paulo, rumo à Argentina ou aos Estados U nidos.

Entre 1941 e 1949, as migrações internas tomaram o lugar das imigrações. São Paulo recebeu 431.153 brasileiros procedentes de outras regiões e somente 45.518 estrangeiros ${ }^{10}$, num processo de substituição de correntes externas que fazia pendant, mutatis mutandis, com o processo de substituição de importações. O riginários da Bahia, de M inas G erais, de Pernambuco, de Alagoas, do Ceará, de Sergipe ${ }^{11}$, chegaram a São Paulo, somente no ano do seu quarto centenário, 94.436 brasileiros, que se incorporaram ao cadinho populacional da cidade e do estado. Pode-se imaginar a força desse segundo impacto na urdidura do tecido cultural urbano.

Fundia-se no espaço da Grande São Paulo uma torrente de línguas e dialetos: as variantes italianas, o calabrês, o napolitano e o vêneto; o português falado pela população mestiça e negra, cultivado no espaço urbano; 0 linguajar caipira chegado com os trabalhadores de origem rural, acrescido do falar mineiro e nordestino, preservador do português arcaico dos tempos coloniais bafejados pelos dialetos africanos e pela língua geral, que ambientaram suas expressões típicas, a entonação de suas alocuções, o movimento descansado de suas expressões ${ }^{12}$.

M as seria um equívoco pensar que os imigrantes, sobretudo os de origem italiana, apegaram-se com exclusividade ao arsenal de atividades produtivas e profissionais urbanas. Em 1920, aproximadamente $22 \%$ das propriedades cafeicultoras estavam nas mãos de estrangeiros; em 1932 essa participação atingia a marca de $36 \%$, dos quais $20 \%$ reservados aos italianos. Reversamente, amplos setores da burguesia agrária, quando tiveram sensibilidade para os novos tempos e não foram colhidos pela decadência irremediável, investiram seus capitais no sistema de transporte ferroviário e nas atividades bancárias, organizando-se em termos mais "modernos", em companhias de capital aberto, por ações, do quea maior parte dos empresários originários da imigração, que formavam sociedades limitadas ao circuito da parentela familiar (cf. Love, 1982, p. 83). U m segundo traço moderno da velha burguesia, segundo J oseph Love, era o fato de "não tenderem a ver a terra como um patrimônio ancestral a ser conservado. Consideravam-na um fator de produção e estavam constantemente a comprar novas propriedades à medida que as antigas perdiam sua fertilidade" (Idem, p. 234) ${ }^{13}$. A elite cafeeira, como se vê, convertia o uso da terra em reserva de valor, num processo de valorização em que as velhas proprieda-
10. "Pode-sepoisconcluir que a imigração, nessecaso a interna, foi extremamentesignificativa para o aumento demográfico deSão Paulo no período em estudo já que o crescimento natural não teria sido suficiente parajustificar os dados eíndicesmencionados. A porcentagem da população paulista atribuível a incremento natural era em 1900 de $34,6 \%$ para a de $65,4 \%$ imputável à imigração. Em 1960 a relação entre esses índices pouco se modificara: $36,1 \%$ e63,9\%, respectivamente" (Quéroz, 1976, p. 490).

11.Ver Boletim do D epartamento del migração e Col onização, São Paulo, 1950, 5: 37-39.

12. A figura de Voltolino expressa a marca do linguajar em São Paulo (ver Beluzzo, s/d; Careli, 1982).

13.0 exemplo emblemático fornecido por Love, se bem que referido ao final do século XIX, é bastante significativo, poistrata-se de uma figura expressiva da burguesia agrária tradicional, 
que chegou a ser governador de São Paulo, JorgeT ibiriçá, que "adquiriu várias propriedadesnaárea servida pela Mogiana e, em 1891, não hesitou em vender a propriedade familiar em Itu" (Love, 1982, p. 234).

14. "Tradicionalmente, a família extensa, ou parentela, constituía parte importante na vida de todos os grupos sociais [...]. M as, na dé cada de 60, as famílias de classe baixa vivendo na capital tendiam a assumir a forma nuclear, ao passo que a família extensa ainda permeava consideravelmente as relações da classe alta" (Love, 1982, p. 124). des se transformavam em moeda de troca para obtenção de terras virgens e férteis. A grilagem ea expropriação forçada foram outros mecanismos, menoslegais e dóceis, de incorporação fundiária. Em qual quer das circunstâncias, a preservação dos espaços de poder político tinha importância capital, pois a combinação bancos-ferrovias-fazendas garantia o conhecimento prévio dos traçados ferroviários em direção à fronteira agrícola e, portanto, das terras que teriam excepcional valorização.

As traj etórias cruzadas de imigrantes ascendidos com a burguesia agrária explicam o perfil singular da mobilidade social em São Paulo nos anos de 1950. A ascensão social dos recém-chegados aos escalões médios e superiores da hierarquia social não significava, obrigatoriamente, descenso dos grupos até então hegemônicos, criando um espaço de acomodação (cf. H utchinson, 1960). A pequena mobilidade substitutiva não significava, necessariamente, o deslocamento abrupto das antigas lideranças econômicas, sociais e culturais, havendo, portanto, uma espécie de colchão amortecedor de tensões, um vácuo de conflitos, capaz de promover a fusão das velhas e das novas elites por via de comunhões familiares. À burguesia decadente restou, finalmente, a fuga para os redutos da cultura - a prosa, a poesia, o teatro - em que, mais uma vez, se encontrará com os recémchegados, por vezes encarnados no papel de mecenas, não raro colegas de ofício.

Para além das meras clivagens sociais, surpreendidas a frio na secura das estatísticas, os autores reais dessa história compartilhada tinham seus espaços de recolhimento, suas muralhas interiores e lugares privilegiados de encontro, particularmente no que tange às elites tradicionais ou emergentes. Enquanto na base da sociedade as classes populares arregimentavam-se em famílias nucleares, no topo, nas famílias da elite, predominava o agrupamento extenso, que não recusava sequer os filhos bastardos, a exemplo de Armando Prado ${ }^{14}$. Sinal inequívoco da capacidade de assimilação das novas elites eram as ritualizações matrimoniais, as celebrações contratuais em negócios comuns, a convivência cotidiana em espaços de lazer. "A alta sociedade incluía agora novos ricos e um círculo de profissionais vindos de cidades menores, que capitalizavam dotes intelectuais ou sociais" (Idem, p. 125), o que não significava a inexistência de um certo ranço crítico em relação à postura e ao comportamento dos novos-ricos, sobretudo de origem imigrante, e que não impedia, contudo, que se confraternizassem no salão de chá, no restaurante do point que era o H otel Jaraguá, ou nas temporadas no balneário de eleição, o Guarujá. 
Tratava-se de uma época com al to grau de dinamismo, na qual a crença nas possibilidades infinitas do desenvolvimento cultural era homóloga à convicção na modernização econômica, social e política que tinha em São Paulo a sua grande promessa. Assim, o presente aspirava o futuro civilizado que, diga-se de passagem, seduzia a todos. Especificamente, produziuse uma confluência do poder econômico e político com o "mundo do espírito", pois todos estavam imbuídos de vontades semelhantes, ainda que dissessem respeito a campos diferentes. Entre o dinheiro e 0 intelecto ocorrem, como afirma Simmel, certas analogias no plano formal, caracterizadas pelo impulso de permanente atualização.

Ao lado da objetividade impessoal inerente ao conteúdo da inteligência existe uma relação extremamente próxima entre inteligência e individualidade [...]. D inheiro, por seu turno, não importa quanto ele transfere modos de comportamento impulsivo-subjetivo para modos suprapessoais e normas objetivas, é, não obstante, terreno fértil para o individualismo e o egoísmo econômico [...]. 0 duplo caminho no qual tanto o intelectual como o dinheiro se tornam inteligíveis éa distinção do seu conteúdo objetivo essencial, de sua função, ou, em outras palavras, nos usos em que são postos (Simmel, 1997, p. 437).

N essa época de crescente diferenciação da cultura e democratização do acesso à vida cultural, movimento fortemente vincado pela presença dos imigrantes, combinadas ao dinamismo econômico, isto é, ao caráter objetivo e subjetivo do dinheiro, as condições indispensáveis para a equalização formal das duas esferas estavam dadas. Por outro lado, a convivência dos grupos culturais com as instituições, os mecenas e, por conseqüência, com 0 ambiente da riqueza, é inerente às metrópoles.

As metrópoles agasalha[va]m as academias tradicionais e os museus em suas ortodoxias. Sua proximidadee poder de controle eram ao mesmo tempo uma estandartização e um desafio. M as, dentro desta sociedade complexa e móvel, pequenos grupos ou qual quer forma de divergência poderiam encontrar [podiam haver encontrado] algum tipo de amparo, o que não teria sido possível em sociedades mais tradicionais e fechadas. A miscelânea metropolitana - a qual no curso do capitalismo e do desenvolvimento do imperial ismo atraiu caracteristicamente uma população variada de diferentes estratos sociais e de origens culturais diversas - e sua concentração de riqueza e possibilidades de mecenato permitiam que esses grupos encontrassem novos tipos de audiência (W illiams, 1997, p. 45). 
15. Ver 0 excelente estudo de Sergio Miceli (1979) sobre as relações entre os intelectuais e o poder.

16. Como ésabido, esse é um fato paulista por excelência, já que no Rio de Janeiro o principal mentor do desenvolvimento artístico e cultural foi o poder público.
Essas relações tornadas efetivas traduziam-se cada vez mais na aproximação com todas as possibilidades de poder, inclusive o político ${ }^{15}$. U ma personalidade como Francisco M atarazzo Sobrinho, o C iccillo M atarazzo, pertencente ao maior grupo empresarial da América Latina e cujo leque de atividades na seara cultural se ancorava em seu poderio econômico, transformava sua riqueza em via de acesso ao reconhecimento social, tornandose figura paradigmática do novo mecenato que então emergia. Afirmava, assim, sua individualidade e o direito de dispor, a seu bel-prazer, dos recursos acumulados na área empresarial, acentuando a dimensão livre da sua personalidade, alforriada dos liames restritivos da condição de imigrante. Ao mesmo tempo, os intelectuais e artistas auferiam novas possibilidades para o exercício de suas ocupações, podendo mobilizar os recursos inerentes aos seus domínios do saber de forma mais segura. N os dois casos, as bases do exercício do mecenato e da vida cultural alteraram-se: em primeiro lugar, porque esse mecenato se direcionou para a criação de instituições, a exemplo dos museus, do teatro e do cinema. Segundo, porque os produtores culturais poderiam usufruir, de modos diversos, da presença das instituições. A confluência dos procedimentos fecha o circuito, o que permite entender como foi possível a associação entre produtores da cultura, empresários e dirigentes, nas comemorações do IV Centenário de São Paulo, em 1954.

É nos quadros dessa universalidade abstrata que a transformação do tecido cultural culmina com a organização de instituições de peso. A multiplicação dos empreendimentos introduziu transformações qual itativas no panorama cultural, fazendo da cidade fonte geratriz das novas expressões em todos os campos.

U mas das grandes marcas distintivas desse período foi a expansão da produção, também fruto das instituições criadas e mantidas por personalidades oriundas do meio empresarial, bem diferentes do mecenato característico dos salões paulistas dos anos de 1920 e $1930^{16}$.

No final da década de 40, o mecenato burguês adquire uma amplitude que a cidade até então não conhecera. E se manifesta sob formas inteiramente diversas. Já não se trata da burguesia cafeeira para a qual a valorização da cultura, no brilho dos seus salões, tem função aristocratizante[...]. E muito menos de um mecenato "benemérito", aplicado à manutenção de pequenas instituições ou de protegidos. Trata-se de um mecenato eminentemente burguês e de uma burguesia industrial suficientemente rica para despender grandes somas de dinheiro (G alvão, 1981, p. 14). 
O riundos da burguesia industrial, de origem predominantemente imigrante, esses mecenas afirmavam-se numa sociedade que começava a familiarizar-se com a ascensão dos estrangeiros. Como bem mostrou Ernani Silva Bruno:

O s italianos e seus descendentes eram às vezes chamados, depreciativamente, de italianinhos ou de carcamanos, pelos brasileiros dotados de longos sobrenomes. M as já não eram italianinhos nem carcamanos os condes e as condessas de nomes peninsulares cruzados, pelo casamento, com gente cujos ancestrais Pedro Taques catalogara na sua $\mathrm{N}$ obiliarquia pauli stana. A miraculosa força do dinheiro começara a derreter os pruridos aristocráticos dos quatrocentões (1986, pp. 52-53) ${ }^{17}$.

D aí a convivência estreita de intelectuais e artistas com as "altas-rodas":

O s escritores, poetas, jornalistas e intelectuais freqüentavam os mesmos lugares compravam, liam etentavam conquistar espaço nas mesmas revistas - e conviviam com as "altas-rodas", sobretudo aqueles interessados em culturalizar o país - os administradores das artes. A vida literária e artística era, então, intensa em São Paulo: todos se conheciam e se encontravam ou aqui (na livraria e salão de chá Jaraguá, por exemplo) ou ali, nas reuniões em casa de amigos ou coquetéis no Automóvel Clube (Pereira, 1987, pp. 37-38).

Em suma, nesse período São Paulo assume a proeminência no âmbito da cultura - até então pertencente ao Rio de Janeiro - ao gestar um padrão cultural diverso. Se os anos de 1920 e 1930 caracterizam-se, de modo geral, pela busca de formas expressivas próprias, o período pós-guerra, em São Paulo, será marcado pelo fortalecimento institucional, pelo mecenato cultural ${ }^{18}$. A participação de estrangeiros, como a do engenheiro Franco Zampari, mas não apenas na realização e implementação, em 1948, do Teatro Brasileiro de Comédia (TBC), expõe a nova face assumida pelo mecenato cultural em São Paulo. Zampari levou para a organização do novo teatro os princípios da ação empresarial.

0 elemento de risco, contido na competição, somado a um mecenato queo atraía formaram um magneto poderoso e irresistível. Por um ângulo temos o homem prodígio, freqüentador das rodas sociais da elite, fascinado desde muito cedo pelo palco e finalmente sentindo a possibilidade de se aproximar dele com maior familiaridade. Por outro, o homem de negócios realizado, o engenheiro empreendedor
17. Estudo recente sobrea origem do empresariado paulista constatou a presença esmagadora de estrangeiros ou descendentes na conformação de seu quadro étnico-social (cf. Pe reira, 1964).

18. $\mathrm{N}$ as palavras de M a riaRitaGalvão: "A ques tão cultural em São Paulo éum problema da burguesia" (1981, p. 22). 
e capaz, diretor das Indústrias M atarazzo, participante de um entusiasmo similar ao que levara seu grande amigo Francisco $M$ atarazzo Sobrinho a criar, no mesmo ano de 1948, o M useu de Arte M oderna de São Paulo. D essa fusão nasce o impulso que conduziria à efetivação do empreendimento que, inicialmente, visava a oferecer uma sede aos artistas amadores paulistas. É possível que a nenhum dos participantes desse primeiro momento tenha ocorrido a dimen são que assumiriam as conseqüências do envolvimento de Zampari com o teatro (Guzik, 1987, p. 13).

O u seja, juntamente com a atração pelos espetáculos teatrais, deve-se considerar a natureza mesma dos investimentos, canalizados para o campo da cultura, mas organizados segundo a lógica das empresas. Tal empreendimento só seria exeqüível se contasse com a presença de profissionais qualificados, raros naquela época no país.

O ito diretores europeus, seisitalianos eum belga ( $M$ auriceVaneau), além de Ziembinski, passaram pelo TBC em seus quinze anos de existência... Revelaram-se pre ciosos, nessa fase de aprendizagem, o virtuosismo de Ziembinski [...] e a sólida formação cênica de Adolfo Celi (o primeiro diretor artístico do TBC). Luciano Salce e Flaminio Bollini (1924-1978), os três diplomados pela Academia de Arte Dramática de Roma. Em complemento a este trabalho de base, estenderam-se muitos deles em outras direções, seja a de cenografia, como Gianni R atto, já reputado profissional ao deixar a Itália, seja a da crítica, como Alberto D 'Aversa (19201969) e, particularmente, Ruggero Jacobbi (1920-1981), autor, entre outros ensaios, de um livro sobre o teatro brasileiro publicado na Itália. A cultura européia, em suma, pesou em todos os níveis, dos técnicos até da difusão de idéias (Prado, 1986, p. 545).

Esses estrangei ros assumiam o papel de "civilizar" - ou seja, profissionalizar - as iniciativas culturais no Brasil, desempenhando as suas funções de modo dirigido e claramente calculado.

Para levantar os fundos destinados à instalação da sala de espetáculo e o capital necessário ao seu funcionamento, Zampari e Ciccillo M atarazzo criaram a Socie dade Brasileira de Comédia, entidade sem fins lucrativos para a qual convidaram duzentas figuras da sociedade paulistana. D ela participaram, entre outros, banqueiros e industriais [...] (Guzik, 1987, pp. 13-14).

Em outros termos, introduz-se uma nova ética na compreensão dos "ne- 
gócios da cultura", e por isso não é de estranhar que os pioneiros fossem predominantemente de origem imigrante, que se aliariam a brasileiros para a montagem das instituições e contariam com um ambiente cultural em franco processo de efervescência, capaz de abrigar as suas idéias ${ }^{19}$.

No caso do cinema, com a criação da Companhia Cinematográfica Vera Cruz - estreitamente vinculada ao TBC e mantida por Ciccillo $M$ atarazzo e Zampari -, repetem-se os mesmos procedimentos.

A Vera Cruz, com seu profissionalismo, alterou radicalmente o setor cinematográfico de São Paulo. Antes, o cinema era uma atividade de pessoas ligadas ao teatro, amadores, descendentes de famílias de imigrantes, principalmente italianos (cf. Galvão, 1975, p. 48). A produção de filmes realizada entre os anos de 1930 e o fim da década de 1940 estava quase total mente restrita ao Rio de Janeiro, ainda queal gumas tentativas de construir projetos empresariais também tivessem fracassado (cf. Gomes, 1996, p. 71; C atani, 1987). No final dos anos de 1940, o ambiente transformase profundamente.

Em 1949 e 1950, cinco companhias cinematográficas são criadas e, nos próximos três anos, a quantidade de produtoras ultrapassa a casa das duas dezenas. Para compreender o surgimento dessa indústria cinematográfica em São Paulo, énecessário examinar a relação entre a burguesia paulista, o mecenato cultural ea cultura cinematográfica que se desenvolvia na capital. A chamada "indústria cinematográfica" paulista surge num momento de intensa atividade cultural em São Paulo (Gomes, 1996, p. 197).

Com a criação da Vera Cruz, um empreendimento de grande envergadura, ao lado de outros como a M aristela e a M ultifilmes, o cinema paulistano assume a liderança da produção nacional (cf. Gomes, 1996; C atani, 1983). No entanto, segundo Paulo Emílio, "os paulistas [...] rejeitaram qualquer paralelo entre 0 que pretendiam fazer e aquilo que se fazia no Rio: renegando a chanchada, ambicionaram realizar filmes de classe e em muito maior número" (Gomes, 1996, p. 76). D esse modo, o projeto cinematográfico deSão Paulo, constituído deforma empresarial, buscava apoiarse na qualidade: "Pela primeira vez surge no Brasil uma companhia cinematográfica que conta com 0 interesse da intelectualidade e da elite financeira paulista" (C atani, 1987, p. 203).

É possível entrever a envergadura da iniciativa nessa ruptura pretendida pelos seus profissionais no que tange à produção cinematográfica no perío-
19. Essasaliançaspodem ser depreendidasdosnomesarroladospor Guzik no levantamento defundos para a criação do TBC (1987, p. 14). 
do antecedente: "A Companhia Vera Cruz foi fundada precisamente para 'criar' uma indústria cinematográfica no Brasil, a partir da estaca zero. Se al guma coisa fica absolutamente clara, desde as suas primeiras tentativas de autodefinição, éa total negação do cinema anterior" (I dem, p. 42). 0 sonho de instalar uma $\mathrm{H}$ ollywood tropical, constituída nos moldes de uma socieda de anônima, parecia rondar o projeto (cf. Idem, pp. 92-93).

A Vera Cruz, quando surge, é auto-suficiente: "Cinema se faz com bons técnicos, bons artistas, maquinaria adequada, grandes estúdios e dinheiro, e a companhia tem tudo isso" (G alvão, 1981, p. 53). N a montagem da equipe técnica, os profissionais e patronos do T BC foram decisivos, e contaram com a colaboração de Assis C hateaubriand, o criador do M useu de Arte de São Paulo, que promoveu conferências de Alberto Caval canti no M ASP, onde já existia o C entro de Estudos C inematográficos (cf. Idem, p. 39). $\mathrm{N}$ as palavras de Cavalcanti:

Em fins de 1949, fui convidado pelo Sr. Assis C hateaubriand para fazer uma série de conferências no M useu de Arte de São Paulo, aqui chegando em 4 de setembro. Como tinha vivido na Europa durante 36 anos, só tendo feito nesse tempo uma viagem de três meses ao Rio, resolvi aceitar. Q uase no fim de minha estada, fui apresentado aos senhores Franco Zampari, Adolfo Celi e Ruggero Jacobbi, pelo Sr. Francisco M atarazzo Sobrinho. Aquelessenhores(todosostrês completamentealheios ao cinema, sob o ponto de vista industrial) convidaram-me para visitar, em São Bernardo do C ampo, os terrenos pertencentes ao último, onde planejavam instalar a futura Companhia Cinematográfica Vera Cruz (apud Gal vão, 1981, p. 96).

A fundação da Vera Cruz pelas mesmas pessoas que estavam na base dos outros empreendimentos exprime a concentração das iniciativas culturais no período, caracterizando o grupo fechado dos mecenas que, neste caso, contou com a presença de Chateaubriand e Pietro M aria Bardi, colaborador na fundação do M ASP, atestando a solidariedade inicial entre os dois grupos. 0 próprio M useu de Arte M oderna - M AM , a mais sólida instituição promovida por Ciccillo, havia sido instalado na sede dos D iários Associados, de Chateubriand, na rua 7 de Abril, onde já funcionava 0 M ASP. A ruptura entre os dois principais mecenas dos museus de arte, Ciccilo e C hateubriand, iria cristalizar-se posteriormente.

0 convite a Alberto $C$ avalcanti foi decisivo para oferecer a qualidade requerida pela iniciativa. $D$ etentor de importantes contatos na área, fruto da longa permanência na Europa, C aval canti contratou técnicos no Velho 
Continente, condição imprescindível à boa produção dos filmes (cf. Penteado, 1976, p. 249). A própria organização do Primeiro Festival Internacional de Cinema, para o qual foram convidados artistas de renome internacional, principal menteamericanos, retrata o quanto de solidez se pretendia conferir à companhia (cf. Idem, p. 245), o que não pôde dispensar inclusive um grande acontecimento social organizado com requinte e sofisticação, a festa na fazenda Empyreo para todos os convidados do festival, por dona Yolanda Penteado, pertencente à tradicional família paulista e na época esposa de Francisco M atarazzo Sobrinho (cf. Idem, pp. 242-254). Tentou-se até mesmo copiar o star system do cinema norte-americano (cf. I dem, pp. 250-251). D iante de tantas pretensões, a Vera Cruz parecia excessiva para o mercado nacional de cinema, e a experiência irá fenecer em 1954. Apesar disso, ela expressou de modo contundente o processo de modernização do tecido cultural paulistano, que teve na criação de instituições sua maior expressão.

No começo da década de 1950, é notória a preocupação em desenvolver um campo cultural diferenciado e mais alinhado com as tendências internacionais. As palavras de Paulo Emílio são reveladoras: "É verdade que sempre houve encontros de intelectuais, discussões sobre arte, política, mil coisas; mas jamais alargado a um número tão grande de pessoas, e prolongado durante tanto tempo e diversificado para tantos campos de interesse" (apud Galvão, 1981, p. 38).

No plano da vivência cotidiana, à ebulição intelectual de São Paulo correspondia a crescente ampliação dos domínios do lazer e do consumo. Em meados da década de 1950, a área da publicidade, índice da pulsação da produção e do consumo, tornava-se um empreendimento empresarial (cf. Arruda, 1985, pp. 93-103). Sintomática a concepção das radionovelas:

A idéia é a nossa matéria-prima. Esta é a nossa indústria, onde trabalham dezoito artistas privilegiados. São os escritores que manejam com os teares da idéia. M ontam a sua produção, desenvolvem-na ea mercadoria, que éo programa, está pronta para a venda. A principal diferença, entre essa indústria e uma outra qualquer, é a de que os recursos da matéria-prima não são palpáveis. H á uma produção em série, mas de conjuntos de idéias diferentes [...]. Essa gama de tendências é posta a serviço do consumo semanal de um espetáculo. Não há usina que iguale essa efervescência de uma fábrica de arte ${ }^{20}$.

Sem dúvida, concepções características da indústria cultural encontram-se
20. Rádio $N$ acional. 20 anos de liderança a serviço do Brasil (19361956). Arquivo M ultimeios, Centro Cultural deSão Paulo, Secretaria Municipal da Cultura, Prefeitura de São Paulo, no 2409, f. 82. D evo a Ana Claudia Fernandez 0 acesso a esse material. 
21. Renato O rtizconsidera "difícil aplicar à sociedade brasileira deste período o conceito de indústriacultural introduzido por Adorno e H orkheimer [...]. Faltavam a elas [as empresas] um traço caracterís tico das indústrias da cultura, o caráter integrador" (1988, p. 48). D e fato, a integração ocorreráapenasno final dos anos de 1960, mas a concepção da mensagem-produto éanterior, como se pode perceber no texto reproduzido.

22. H eloísa Almeida apresenta dados sobreo número de lugares e a freqüência anual aoscinemas entre os anos de 1940 e 1970.0 movimento de ascensão nos doisíndicesentre19401960 dedinaentre 1960 e 1970, momento em quea televisão começava a interferir na freqüência aoscinemas. M asentre 1940 e 1960 osnúmeros são eloqüentes: $\mathrm{N}$ úmero de lugares 1940 (95.754);

1945 (122.736);

1950 (158.000);

1955 (199.379);

1960 (224.669).

Público anual

1940 (19.526.224);

$1945(30.212 .942)$;

1950 (35.846.722); em pleno processo de implantação, explicitada na concepção da mensagem como mercadoria21.

0 consumo cultural ampliara-se consideravelmente, como se pode depreender da grande afluência de público aos cinemas, que nos anos de 1949 e 1950 viviam "a sua idade de ouro", tornando o empreendimento altamente lucrativo (cf. Almeida, 1996, p. 161)²2. Em conseqüência, a realização do Primeiro Festival Internacional de Cinema no Brasil, no ano do IV Centenário de São Paulo, coroou um movimento de enraizamento da cultura cinematográfica na cidade ${ }^{23}$. 0 cinema ea publicidade eram as áreas mais visíveis da americanização dos modos de vida, o que, de resto, estava igualmente acontecendo na música popular e no próprio teatro, e já havia ocorrido nas concepções urbanistas desde o "Plano de Avenidas" de Prestes $M$ ai $a^{24}$. A ascendência dos padrões norte-americanos no âmbito da cultura significava deslocar a hegemonia cultural francesa, típica das nossas elites europeizadas, mas denotava, conjuntamente, certa concepção de como organizar as atividades, que em São Paulo se fará sob o signo empresarial: nos meios de comunicação, na publicidade, no cinema, no teatro. N aturalmente, os limites desses empreendimentos levados a efeito no período eram visíveis, como aponta Renato O rtiz, e o chamado "espírito da racionalidade" combinava-se "a padrões mais antigos", como se percebe quando da inauguração daTV Tupi por Assis C hateaubriand ${ }^{25}$. Apesar disso, é possível a ocorrência de projetos empresariais no âmbito da cultura, o que não significa reduzi-Ios às puras manifestações da visão burguesa ${ }^{26}$.

Entender essas iniciativas pressupõe considerar a relação entre esses empreendedores e a intelectualidade paulistana que promoveu, amparou e participou ativamente de grande parte das instituições em processo demontagem, como foi o caso de Sérgio M illiet, dos jovens do Grupo Clima e de outras personalidades da vida cultural de São Paulo ${ }^{27}$, em consórcio com os estrangeiros, essenciais à formação do corpo técnico do T BC e da Vera C ruz e cujo papel foi decisivo na modernização dos diversos setores da cultura, chegando a extrapolar esse período com a atuação das "missões" na fundação da Universidade de São Paulo, em 1934 (cf. M assi, 1989; 1991). N esse andamento, a compreensão das diversas instituições criadas no pósguerra em São Paulo não se completa se não lidarmos com a natureza do seu fenômeno imigratório, numa época em que os herdeiros das famílias de estrangeiros já ascendidas buscavam legitimar-se socialmente, o que significa a superação da mera questão demográfica ou do movimento em direção às posi ções sociais superiore ${ }^{28}$. A conexão entre o modernismo e o 
fenômeno da imigração, estabelecida por Raymond Williams, pode ser estendida ao campo da construção das instituições culturais que, em São Paulo, ofereceram o solo propício ao vicejamento das linguagens. Para ele, "a chave fundamental das mudanças do estilo modernista é o caráter das metrópoles. 0 impacto mais importante é seus efeitos na forma, e o fato mais importante das mudanças na forma é a imigração para as metrópoles [...]" (1997, p. 45).

No conjunto, a cultura desse meio século XX reproduzia a mélange característica de uma sociedade em vigoroso movimento transformador, mas estava submetida às tensões de uma história sem força suficiente para promover rupturas mais profundas. 0 tecido cultural daqueles anos pode ser caracterizado como uma "cultura de mescla, na qual coexistem elementos defensivos e residuais ao lado de programas renovadores" (Sarlo, 1997, p. 217). Esse diagnóstico sobre Buenos Aires a partir dos anos de 1930 aplica-se a São Paulo29.

0 sistema de respostas culturais formado nesses anos terá importante influência até, pelo menos, a década de 1950. Trata-se de um período de insegurança mas também de certezas muito fortes, de releituras do passado e de utopias, no qual a representação do futuro e da história entram em choque nos textos e nas polêmicas. A cultura de Buenos Aires estava sujeita à tensão do "novo", muito embora também se lamentasse do curso inexorável das mudanças [...]. A modernidade é um cenário de perdas mas também de fantasias reparadoras. 0 futuro era hoje (Petrone, 1955, p. 217).

D a vivência dessa tensão, as linguagens da cultura retirarão o seu impulso, como foi o caso das artes.

O s museus de arte de São Paulo foram criados, então, numa conjuntura tensa, atravessada por fortes dissensões que grassavam no ambiente cultural e intelectual da cidade. 0 aparecimento dessas instituições deu-se num momento fervilhante de debates, que polarizavam artistas, escritores e intelectuais, envolvidos nas polêmicas sobre a cultura de participação, da arte social, que estavam na base de conflitos que envolveram antigas e novas gerações em torno da questão real ismo-abstracionismo. Convivia-se com uma situação, em certa medida, paradoxal. Enquanto em outros países as vanguardas ofereceram combate sem trégua aos museus, aqui as instituições foram em geral bem-vindas e até calorosamente acolhidas, caso específico dos museus de arte moderna ${ }^{30}$. 0 M AM de São Paulo, oficial-
$1955(57.736 .902)$

1960 (44.357.881).

A autora mostra que já "no final dosanosde 30 , começou a se formar a Cinelândia paulista na região do centronovo, nas avenidasSão João, Ipiranga eimediações" (1996, p. 162). Os maiores cinemas deSão Paulo localizavam-se no Brás, bairro operário ede origem imigrante(cf. Idem, p. 163). Nos anos de 1940, São Paulo possuía 449 tipografias, 203 revistas, 106 livrarias, 91 jornais (em várias línguas), 45 casas editoras e 150 cinemas (cf. Petrone, 1955, p. 168).

23. 0 Festival compreendia a Retrospectiva do Cinema Brasileiro, o Festival do Cine ma Científico, o Festival de Cinema para as Crianças, conferências, publicações e exposições, como as realizadas no M useu deArte M oderna, sobre as obras de Erich von Stroheim e Abel $\mathrm{G}$ ance. Ver "C ine ma de 30 D ias", Revis ta Anhembi, 45 (XV), ago. 1954.

24. “N ão se pode esquecer que os anos 40 marcam uma mudança na orientação dos modelos estrangeiros entre nós. 0 s padrões 
europeus vão ceder lugar aos valores americanos, transmitidospela publicidade, pelo cine ma e pelos livros em língua inglesa que começam a superar em número as publicações de origem francesa" (O rtiz, 1988, p. 71). "Ao Brasil, restava continuar na esteira da coIonização cultural. N o plano musical, chegavam até nos ritmos como o swing, o jazz e o boogie woogie" (Caldas, 1995, p. 105). "N esse sentido, Prestes Maia, no seu Plano de Avenidas, até apresentava uma inovação: a incorporação das idéias dosurbanistas americanos, caracterizadas pelo movimento C ity Beautiful [...] etambém pe lasidéias mais atuais da época, tais como o planejamento da circulação e a legislaçãa do zoneamento" (Somekh, 1997, p. 139). No teatro, a presença da dramaturgia norte-americana é incontestável: autores como Arthur M iller e 0 ' $N$ eill eram encenados com freqüênciae foram importantes à elaboração da obra dejorgeAndrade.

25. "Eu diriaqueo empresário cultural dos mente inaugurado em 8 de março de 1949, desempenhou papel fundamental na divulgação das novas linguagens ao propiciar as condições de acesso dos artistas brasileiros às novas ten dências pictóricas mundiais. Eventos como as bienais de arte, promovidas pelo M AM a partir de 1951, alinhavam os brasileiros com a arte abstrata, criando um ambiente favorável às apropriações. Ao mesmo tempo, as exposições periódicas e o conjunto de eventos e iniciativas que o museu implementou ofereciam novas possibilidades de ingresso ao universo das linguagens das vanguardas. 0 próprio M ASP, com o seu acervo eclético, permitiu que se fizessem aproximações com o desenvolvimento das artes plásticas no 0 cidente, revelando evidente caráter pedagógico. Em contrapartida, o M AM oferecia uma mostra da formação pictórica que poderia ser contrastada com os experimentos contemporâneos. Talvez por isso os museus tenham recebido aprovações generalizadas, o que não significava, no entanto, unanimidade em relação aos projetos, ou mesmo quanto aos métodos utilizados na formação dessas instituições (cf. Amaral, 1987, pp. 245-250). A despeito das críticas, principalmente aos procedimentos de Assis C hateaubriand, o controvertido fundador do M ASP, assim como a seu braço forte, Pietro M aria Bardi, os museus carregavam promessas civilizatórias que agradavam a todos. 0 M useu de Arte M oderna do Rio de Janeiro, similarmente, reequilibrava em parte a perda de espaço da capital diante das iniciativas paulistas. N o conjunto, a todos parecia que o país se tornava culturalmente mais denso, mais ilustrado, apesar de os atos do primeiro governo da recéminstalada democracia parecerem querer desmentir os ares cosmopolitas. M as a produção industrial havia superado a cafeicultura já em 1946 e 0 país se abria para a construção da sociedade moderna. 0 futuro afiguravase auspicioso, o que se comprovava com a novidade de um tipo de mecenato incomum até então: diferentemente do projeto de fundação da U niversidade de São Paulo, no qual "elites ilustradas" se consorciaram com 0 governo estadual, que acabou atuando como agente viabilizador da instituição, os mecenas dos museus eram empresários, fato sintomático do vigor das atividades econômicas no Brasil. Além de empreendedores, lançaram-se na construção desses organismos culturais de cunho público, necessariamentearticulando ações arrojadas eaté mesmo aventureiras, quando se considera a efetiva realidade brasileira. Independentemente dos problemas que costumam acompanhar iniciativas dessa natureza, mormente em contextos como o nosso, os museus renovaram a cultura das artes na cidade ao possibilitarem o contato direto de artistas e do público com 
obras clássicas, modernas e contemporâneas. Introduziram, sobretudo, um clima qualitativamente diverso, em função da organização de iniciativas em múltiplas direções, permitindo a São Paulo e à capital do país alinharem-se com o ritmo cultural dos grandes centros mundiais.

A literatura que trata da conjuntura de criação dos museus de arte no Brasil, no segundo quartel dos anos de 1940, acentua, comumente, as relações entre as transformações da sociedade brasileira no período, resultantes da industrialização, da democratização, enfim, da modernização, e as mudanças no âmbito da cultura, que se tornava concomitantemente mais complexa ${ }^{31}$. N os textos produzidos no interior das instituições, até nos mais analíticos, emergem conexões dessa natureza. D esse modo, as análises de cunho contextual inserem as instituições museológicas nos quadros da sociedade brasileira que se desenvolvia e se modernizava, atestadas pelo dinamismo das grandes cidades e de São Paulo em particular.

0 mesmo ocorre quando se busca a conexão dos museus de arte com a conjuntura internacional no pós-guerra e, especificamente, com a política norte-americana para a América Latina. N esse caso, trata-se de salientar os aspectos essencialmente externos ao empreendimento dos museus e entender a formação desses organismos como produtos das políticas de dominação e civilizacional dos países hegemônicos. Como diz M aurício Parada: "O s museus de arte moderna, fundados nessa década em todo o mundo, foram parte integrante da propaganda americana contra o grande prestígio desfrutado pelo socialismo entre intelectuais e artistas" (s/d, p. 25). É possível combinar essa mesma linha de raciocínio com as vertentes de análise do caráter tributário das instituições da cultura às ações de grupos esclarecidos da classe dominante, ou dos seus representantes, que desenvolviam uma pedagogia em relação à sociedade com a intenção de educá-la $a^{32}$. Por certo, não está completamente afastada desse domínio a acentuação do papel dos patronos, os mecenas propriamente ditos, seja como lídimos representantes da sua classe, seja pelo enredamento do perfil assumido pela instituição nos traços característicos de suas personalidades, moldadas no percurso dos seus itinerários pessoais (cf. Bardi, 1992; Almeida, 1976) ${ }^{33}$. N esse tipo de abordagem, que comumente ultrapassa o terreno da reflexão, desembocando no mais puro discurso panegirístico, costuma-se identificar a organização com a capacidade e o espírito empreendedor do seu formador; na contraface desses discursos, as iniciativas dos promotores transformam-se em meros instrumentos, ao transmutarem-se em recursos para 0 atingimento de fins individuais, de prestígio ou de realização de interesses anos 40 e 50 se aproxima ao que Fernando $\mathrm{H}$ enrique define como capitão da indústria" (Ortiz, 1988, p. 57). Esse livro traz um ótimo panorama dessas questões no período. Um bom relato da precariedade dos métodos de Chateaubriand, na ocasião da inauguração da TV Tupi encontra-se no livro de Fernando Morais: "Um mês antes do dia $D$, o engenheiro norte-americano Walther 0 bermüller, diretor da NBC-TV, veio ao Brasil para supervisionar a inauguração e asprimeiras semanas do funcionamento daTupi [...]. 0 americano quis saber 'quantos milhares de receptores tinham sido vendidos pelo comércio à população de São Paulo'. Os dois diretores se entreolharam eresponderam quaseem coro: 'Nenhum'. Atônito com anotícia, 0 bermüller pediu uma reunião com Chateaubriand, para advertir o dono dos Associados [...]. Chateaubriand dissepara ele não esquentar a cabeça com aquilo, que no Brasil tudo tinha solução" (1994, p. 500).

26. Ver O rtiz (1988, pp. 67-70) sobre o caráter 
burguês dosinvestimentos, não necessariamente da presença de orientação burguesa no plano cultural. Antonio C andido (1980) contesta, significativamente, a concepção queidentifica os empreendimentos culturais à burguesia.

27.0 único grande empreendimento que foi visto com ceticismo pelos intelectuais paulistasfoi o M ASP, uma vez que os métodos de Chateaubriand para a montagem do acervo eram considerados no mínimo discutíveis. Sobreaimportância de Clima na cultura em São Paulo, ver o excelente trabalho de $\mathrm{He}$ loísa Pontes (1998).

28.Sobre a geografia urbana de São Paulo e o fenômeno demográfico, o livro organizado por Aroldo de Aze vedo (1958), e concebido como homenagem ao IV Centenário da cidade, apresenta uma visão ampla. O s italianos de origem foram centrais às novasiniciativas. Para uma análise ampla dessa imigração, ver Trento (1989). Para a participação dos italianos no teatro brasileiro desde as origens das encenações promo- colimados ${ }^{34}$. Finalmente, outra via de compreensão encontra-se presente no corpo de estudos que inserem a formação desses institutos no quadro de amadurecimento do tecido cultural do país: os museus de arte seriam tributários do adensamento da linguagem artística que, ao atingir certo patamar, desemboca na inevitável criação dos seus organismos pertinentes (cf. Zanini, 1983, 1991; Lourenço, 1990; Amaral, 1982). 0 problema de tais abordagens reside no isolamento da produção cultural, que se desprega das condições sociais, resvalando para uma espécie de visão progressiva da linguagem, enfocada nos seus próprios termos. Como conseqüência, essas reflexões tendem a identificar as instituições, uma vez criadas, com representações do progresso do setor, desempenhando o papel de êmulos das alterações das linguagens artísticas, dotados da qualidade de moldar a gramática das obras e dos estilos ${ }^{35}$.

Se é de todo evidente que as transformações ocorridas no Brasil e no cenário internacional no pós-guerra são fundamentais para a criação dos museus de arte, é também válido reconhecer que as conexões não se dão por simples imbricação. Do ângulo das condições emuladoras, cabe reconhecer o papel considerável do processo de democratização e de desenvolvimento ocorrido no Brasil, nesse período. Similarmente, o contexto externo, tanto europeu como norte-americano, favorecia a intensificação das relações, com o deslocamento de artistas para as Américas, o rebaixamento do preço das obras de arte no Velho Continente, a nova reaproximação com os Estados Unidos, ainda que arrefecida durante o Estado N ovo, e finalmente a passagem do eixo artístico de Paris para N ova York. A política de aliança preferencial com os Estados U nidos facilitou, como se sabe, a montagem dos museus de arte moderna. No conjunto, as mudanças no âmbito interno e externo construíram o pano de fundo da formação dessas instituições ${ }^{36}$. No plano mais específico, a industrialização e a urbanização provocaram a diferenciação da estrutura social, de complexidade crescente. As funções empresariais, conseqüentemente, diversificavam-se e novos nichos profissionais abriam-se para as profissões intelectuais. Em São PauIo, a emergência dessa camada empresarial moderna e potente, em termos de América Latina, transfigurava o mundo dos outrora dominantes, produzindo uma classe trabal hadora numerosa, com a conseqüente ampliação do setor de serviços e das novas profissões, o que provocou a diversificação das ocupações típicas das classes médias. 0 êxito da U niversidade de São Paulo democratizou 0 acesso à instrução superior e permitiu a entrada maciça nos quadros universitários dos filhos dos estratos médios, nublan- 
do as constrições referentes à origem. A determinação do contexto familiar, se ainda não era de todo ausente, arrefecia-se no interior da vida social em São Paulo.

No conjunto, alterou-se o exercício das chamadas profissões culturais, pois novos lugares emergiram nos ensinos secundário esuperior, na grande imprensa - que, desdeosanos de 1930, vinha se desenvolvendo em moldes empresariais e absorveu um contingente significativo de profissionais de formação superior (cf. Sodré, 1977, pp. 427-428) -, na publicidade, nas artes industriais, abrigando profissionais universitários, principalmente em São Paulo eno Rio de Janeiro. N a capital da República, a modernização do aparelho do Estado, iniciada no primeiro governo Vargas e intensificada no segundo, pressupôs a assimilação de uma elite cultural, além da profissionalização da estrutura burocrática. 0 Rio de Janeiro, na condição decentro administrativo, era o pólo de atração dos ilustrados brasileiros por oferecer maiores oportunidades profissionais, ao facilitar o acesso ao mecenato oficial recorrentemente desenvolvido pelo Estado. 0 grande capital financeiro, sediado na cidade desde o período cafeeiro, convivia com empresas de comercialização e exportação de porte considerável. 0 processo de modernização e a abertura democrática, expuseram suas faces política e social. N ecessariamente a produção cultural não ficaria imune à dinâmica do todo: ampliou-se em quantidade, mas, principalmente, diversificou-se no âmbito das linguagens modernas.

Em São Paulo, desde o terceiro decênio e, caracteristicamente, nas dé cadas de 1940 e 1950, vivia-se da mesma forma o fenômeno da diversificação das elites, que vicejavam no terreno da modernização e chegaram, em meados do século, à condição de poderem propor a organização de instituições de natureza pública. D aí terem esses projetos institucionais assumido "feitio civilizatório". Preocupação dessa natureza transpira nas frases de Ciccillo M atarazzo:

Antes disso, Assis C hateaubriand havia fundado o M useu de Arte de São Paulo. Eu era muito amigo dele. Uma vez, convidou-me para almoçar na sede do velho Automóvel Clube, muito fechado, na época. Perguntou por que não nos juntávamos para realizar ali mesmo uma grande manifestação de arte, como eu pretendia fazer da Bienal. Respondi-Ihe que não. 0 que ele queria fazer para um grupo de iniciados e privilegiados, eu desejava fazer para o povo, para o homem da rua [...].

Com essas palavras, Ciccillo M atarazzo toca, implícita e não intencional- vidas por imigrantes, ver Silveira (1976). A participação dos estrangeiros desdobrou-seno plano da crítica, como no caso do papel central deAnatol Rosenfeld e Jean-Claude Bernardet em São Paulo e, no Rio de Janeiro, deO tto $M$ aria Carpeaux.

29. Se a construção de prédiospode ser um indicador seguro para 0 padrão de desenvolvimento deuma determinada metrópole, os ritmos de São Paulo e Buenos Aireseram próximos e superiores até mesmo a Nova York: "Enquanto em Nova York constrói-se, a cada ano, uma casa para cada grupo de 423 habitantes, em Buenos Aires para 134, em São Paulo registra-se a média de 102". Portanto, "parecenão existir nenhuma cidade que se iguale", evidentemente, a São Paulo (Petrone, 1955, p. 167).

30. “Foi após todo o movimento de vanguardas históricas - futurismo, dada, surrealismo, construtivismo e os grupos de vanguardas da recém-instalada União Soviética - que se começou uma luta radical e implacável 
contra os museus. Essa luta começa na exigência do fim do passado através da destruição semiológica de todas as formas tradicionais de representação e ao se defender a ditadura do futuro. Paraaculturade manifestos[...] o museu realmente era um bode expiatório plausível" (H yssen, 1997, p. 228). 31. "O novo surto industrial vem a alterar 0 perfil sociocultural do país: crescer a migração do campo para as cidades e neste processo a tradição rural e artesanal cede terreno à cultura urbana e à industrialização. É na dinâmica destas mudanças que ocorreo advento do abstracionismo em evidente confronto com a arte então centrada na repre sentação do homem e seu meio", em "Abstra ções (145-160)", Bienal Brasil, Arquivo M AC.

32. "Pela sua atuação educacional, o museu moderno deve atuar junto à população urbana, educando-a para que obtenha a competência estéticaecomportamental necessárias a um país que pretende superar os desafios do crescimento econômico" (Parada, $s / d$, p. 62). mente, numa questão fundamental, que diz respeito à emergência de uma esfera pública burguesa na sociedade brasileira, em lento processo de constituição, que brota na esteira da modernização e da democratização instauradas no pós-guerra ${ }^{37}$. Penso ser esse 0 significado mais profundo desse mecenato privado, originado numa sociedade capitalista que, ainda que periférica, ganhava os contornos de "civilização moderna", expressos nas ações de sujeitos oriundos das atividades privadas. Essa "nova ética" orientada para o mundo público distinguia tais personalidades, a despeito de suas clivagens, das elites do passado. Tais mudanças, manifestadas sobretudo em São Paulo, nos planos mais visíveis da economia e da estrutura social e no âmbito político, haviam fundado na sua ratio uma energia que transbordava para as efferas da convivência pública. Audácia e hábito em convívio com o risco, atributos indissociáveis à ética empresarial, eram qualidades imprescindíveis à construção de instituições da magnitude dos museus, do teatro, da indústria cinematográfica. M odificavam-se, assim, as relações entre as pessoas privadas e a vida social, estabelecendo-se uma empatia entre os interesses e a esfera do coletivo.

Foi exatamente no bojo desses experimentos civilizatórios, ocorridos na cidade de São Paulo nesse período, que vicejaram as linguagens culturais mais renovadoras, como o concretismo na poesia e nas artes plásticas; a dramaturgia e a cinematografia; a arquitetura, o design, a publicidade; as ciências sociais e o planejamento urbano; os debates que grassavam em todos os campos, a exemplo das celeumas sobre figurativismo e abstracionismo; a arte social, nacional e universal; a ciência rigorosa e o conhecimento engajado. 0 vigor cultural em curso forjou-se na dinâmica da modernidade burguesa, imersa na crença no progresso irreversível e comprometida com a construção do poder do dinheiro. A esfera social havia adquirido complexidade incomparável com aquela que viu emergir o impulso vanguardista do decênio de 1920. A nova experimentação modernista ocorria num ambiente permeado por concepções heterogêneas sobre a criação cultural, vindo a reforçar o pluralismo deSão Paulo em franco movimento de construção das linguagens futuras. O s impasses que ocorrerão nos anos vindouros não conseguiram apagar os impulsos da renovação brotados nesse meio século de mudanças indeléveis; tampouco foram suficientes para destruir o significado das instituições na vida da cidade tornada metrópole, de cujo legado ainda somos herdeiros. 
Referências Bibliográficas

Alm eid A, Fernando Azevedo de. (1976), 0 franciscano Ciccillo. São Paulo, Pioneira. Alm EIDA, H eloísa Buarque de. (1996), "Janela para o mundo". In: M agnanı, José Guilherme C.\& T ORREs, Lilian de Lucca (orgs.). N a metrópole: textos de antropologia urbana. São Paulo, Edusp.

Am ARAL, Aracy A. (1982), A arte e meio artístico: entre a feijoada e o x-burguer. São Paulo, Studio Nobel. . (1987), Arte para quê? A preocupação social na arte brasileira, 1930-1970. São Paulo, N obel.

Araú jo, J. R. (1958), "A população paulistana”. In: Azevedo, Aroldo de (org.). A cidade de São Paulo: estudo de geografia urbana. São Paulo, Companhia Editora N acional, vol. II.

Arruda, M aria Arminda do N ascimento. (1985), A embalagem do sistema: a publicidade no capitalismo brasileiro. São Paulo, D uas Cidades.

Azevedo, Aroldo de (org.). (1958), A cidade de São Paulo: estudos de geografia urbana. São Paulo, Companhia Editora N acional.

Barata, M ário. (1971), Presença de Assis Chateaubriand na vida brasileira. São PauIo, $M$ artins.

BardI, Pietro M aria. (1992), Soldalício com Assis Chateaubriand. São Paulo, M ASP/ ARP.

Belluzzo, Ana M aria de M . (s/d), Voltolino e as raízes do modernismo. São Paulo. D issertação de M estrado. Faculdade de Arquitetura e U rbanismo da Universidade de São Paulo.

Brun o, Ernani Silva (1986), Almanaque de memórias: reminiscências, depoimentos, reflexões. São Paulo, H ucitec.

Caldas, Waldenyr. (1995), Luz néon: cultura na cidade. São Paulo, Sesc/Studio Nobel.

Candid 0, Antonio. (1980), "Feitos da burguesia". In: Teresina etc. Rio de Janeiro, Paz e Terra.

CAN o, W ilson. (1977), Raízes da concentração industrial em São Paulo. São Paulo, Difel.

(1985), D esequilíbrios regionais e concentração industrial no Brasil, 1930 1970. São Paulo, Global.

C Arelli, M ário. (1982), Carcamanos \& comendadores O sitalianos de São Paulo: da realidade à ficção. São Paulo, Ática.

Catanı, Afrânio M endes. (1983), A sombra da outra: um estudo sobrea cinematográfica M aristela e o cinema industrial paulista nos anos 50. São Paulo. Dissertação
33. "C hateaubriand tinha- paralelamenteaos seus impulsos fundamentais pela ação prática - especial atenção pelosvaloresvisuais, que revelava desdeo interessejuvenil pela paisagem do nordeste e 0 artigo de 1952 sobrea obrade Tarsila e a amizade por Visconti a partir dessa época, e certa ternura por Portinari, mais tarde, atéculminar nas visitasquefazia a museus, pelo mundo afora, ena referida criação do M ASP" (Barata, 1971, p. 103).

34. A alusão de que Chateaubriand criou 0 M ASP tendo em vista a sua rede de veículos de comunicação pode ser encontrada em D urand (1989) e Silveira (1983).

35. "O que de notável sucede, em matéria de institucionalização da arte moderna, fica por conta da implantação de entidades museais, no pós-guerra [...]. A entrada de recursos, por um lado vindo de Assis Chateaubriand e por outro de Francisco M atarazzo Sobrinho, modifica totalmente 0 meio brasileiro" (Lourenço, 1990, p. 308). 
Em seu livro de 1999, Lourenço apresenta uma visão mais matizada do problema.

36. "O s clamores pela criação de um M AM intensificam-se entre nós, no pós-guerra [...]. Adota-seo modelo norteamericano, afinal um padrão cultural desejá vel após a aproximação com osEstadosU nidos, apoiada pelos intelectuais, queentendiam-na como indispensável para afastar Getúlio Vargas do nazifascismo, estratégia plenamente atingida" (Lourenço, 1999, p. 19).

37. “A esfera pública burguesa desenvolvida baseia-sena identidade fictícia das pessoas privadas reunidas num público em seus duplos papéis de proprietários edemerosseres humanos" (H abermas, 1984, p. 74). de M estrado. Faculdade de Filosofia, Letras e C iências H umanas da U niversidade de São Paulo.

. (1987), "A aventura industrial e o cinema paulista (1930-1945)". In: Ram os, Fernão (org.). H istória do cinema brasileiro. São Paulo, Art Editora.

D EAN, Warren. (1971), A industrialização em São Paulo. São Paulo, D ifusão Européia do Livro.

D URAN D, José C arlos G arcia. (1989), Arte, privilégio e distinção: artes plásticas, arquitetura e classe dirigente no Brasil, 1855/1985. São Paulo, Perspectiva.

Galvão, M aria Rita. (1975), Crônica do cinema paulistano. São Paulo, Companhia Editora N acional.

- (1981), Burguesia e cinema: o caso Vera Cruz. Rio de Janeiro, Civilização Brasileira.

Gomes, Paulo Emílio. (1996), Cinema, trajetória do subdesenvolvimento. São Paulo, Paz e Terra.

Gottdiener, M ark. (1997), A produção social do espaço urbano. São Paulo, Edusp.

Guzık, Alberto. (1987), TBC. Crônica de um sonho: o Teatro Brasileiro de Comédia (1948-1964). São Paulo, Perspectiva.

H AbeRm AS, Jürgen. (1984), M udança social na esfera pública. Rio de Janeiro, Tempo Brasileiro.

H UTCHIN SON, Bertram et alii. (1960), M obilidade e trabalho: um estudo da cidade de

São Paulo. Rio de Janeiro, Instituto N acional de Estudos Pedagógicos.

H YSSEN , Andréas. (1997), M emórias do moderni smo. Rio de Janeiro, Editora da U FRJ. Lo uren ço, M aria Cecília França. (1990), M aioridade do moderno em São Paulo: anos

30/40. São Paulo. Tese de D outorado. Faculdade de Arquitetura e U rbanismo da Universidade de São Paulo. . (1999), M useus acolhem moderno. São Paulo, Edusp.

Love, Joseph. (1982), A locomotiva: São Paulo na Federação Brasileira 1889-1937. São Paulo, Paz e Terra.

[M assi] Peixoto, Fernanda. (1989), "Franceses e norte-americanos nas ciências sociais brasileiras". In: M ICELI, Sergio (org.). H istória das ciências sociais no Brasil. São Paulo, I desp/Vértice, vol. I. . (1991), Estrangeiros no Brasil: A mi ssão francesa na U SP. C ampinas. D issertação de M estrado. Unicamp.

M ello, João M anuel Cardoso. (1982), 0 capitalismo tardio. São Paulo, Brasiliense. M eyer, Regina M aria Prosperi. (1991), M etrópole e urbanismo: São Paulo anos 50.

São Paulo. Tese de D outorado. Faculdade de Arquitetura e U rbanismo da U SP. M ICELI, Sergio. (1979), Intel ectuais e classe dirigenteno B rasil (1920-1945). São Paulo, Difel. 
M orais, Fernando. (1994), Chatô, o Rei do Brasil. São Paulo, Cia. das Letras.

O RTIZ, Renato. (1988), A moderna tradição brasileira: cultura brasileira e indústria cultural. São Paulo, Brasiliense.

Parada, M aurício B. A. (s/d), A fundação do M useu de Arte M oderna do Rio de Janeiro: a elite carioca e as imagens da modernidade no Brasil dos anos 50. Rio de Janeiro. D issertação de M estrado. PU C.

Penteado, Yolanda. (1976), Tudo em cor-derosa. Rio de Janeiro, N ova Fronteira.

Pereira, José Carlos. (1967), Estrutura e expansão da indústria em São Paulo. São Paulo, Companhia Editora N acional.

Pereira, Luiz C arlos B resser. (1964), “O rigens étnicas e sociais do empresário paulista". Revista de Administração de Empresa, São Paulo, FGV, 4 (11): 83-106.

Pereira, M ônica de S. G. (1987), Anhembi: criação e perfil de uma revista de cultura. São Paulo, Idesp. (Série H istória das Ciências Sociais no Brasil, no 2.)

Petrone, Pasquale. (1955), "A cidade de São Paulo no século XX". Revista de H istória, São Paulo, 21-22 (VI): 167, jan.-jun.

Pontes, H eloísa. (1998), D estinos mistos: os críticos do Grupo Clima em São Paulo (1940-1968). São Paulo, Cia. das Letras.

Prado, D écio deAlmeida. (1986), "Teatro: 1930-1980 (Ensaio deinterpretação)". In: Fausto, Boris (org.). H isćria geral da civilização brasileira. São Paulo, Dife, tomo III, vol. 4.

Quelroz, Suely Robles Reis de. (1976), "São Paulo (1875-1975)". Revista de H istória, São Paulo, 108 (LIV): 490.

Sarlo, Beatriz. (1997), "Buenos Aires, cidade moderna”. In: . Paisagens imaginárias. São Paulo, Edusp.

Silveira, H elena. (1983), Paisagem e memória. Rio de Janeiro, Paz e Terra.

SILVEIRA, M iroel. (1976), A contribuição italiana ao teatro brasileiro. São Paulo, Q uirón/ $M E C$.

Sim mel, George. (1997), The philosophy of money. Londres, Routledge.

SIn Ger, Paul. (1974), D esenvolvimento econômico e evolução urbana. São Paulo, Companhia Editora N acional. . (1983), E conomia política da urbanização. São Paulo, Brasiliense.

So d RÉ, N elson Werneck. (1977), H istória da imprensa no Brasil. Rio deJaneiro, Graal. So m EKH, N adia. (1997), A cidade vertical e o urbanismo modernizador. São Paulo, Studio N obel/Edusp.

SouzA, M aria Adélia A. (1994), A identidade da metrópole. São Paulo, H ucitec.

Trento, Ângelo. (1989), D o outro lado do Atlântico: um século de imi gração italiana no Brasil. São Paulo, N obel.

W ILLIAMS, Raymond. (1997), The politics of modernism: against the new conformists. Londres, Verso. 
ZanINI, Walter (org.). (1983), H istória geral da arte no Brasil. São Paulo, Instituto M oreira Salles/Fundação D jalma Guimarães. . (1991), A arte no Brasil nas décadas de 1930-40. São Paulo, Studio N obel.

\section{Resumo}

Empreendedores culturais imigrantes em São Paulo de 1950

Este artigo discute as relações entre imigração, indústria, diversificação das elites e criação das instituições culturais em São Paulo nos anos de 1950, momento deintenso dinamismo da cidade que adquiria os contornos definitivos de metrópole. Como conseqüência dessas mudanças, solidificou-se a compreensão do caráter civilizatório contido no desenvolvimento cultural, estabelecendo-se franca homologia com a modernização em curso, em todas as esferas da sociedade. $\mathrm{N}$ a esteira dessas iniciativas, vicejaram as linguagens culturais mais renovadoras, caso do concretismo na poesia e nas artes plásticas; da dramaturgia e da cinematografia; da arquitetura, do design, da publicidade; das ciências sociais e do planejamento urbano; dos debates que grassavam em todos os campos. 0 vigor cultural do período forjou-se na dinâmica da modernidade burguesa, identificada com o progresso e comprometida com a construção do poder do dinheiro.

Palavras-chave: Imigração; Empreendedores culturais; Instituições da cultura; São Paulo; M etrópole.

Texto recebido em 29/ 9/2004 eaprovado em $10 / 1 / 2005$.

MariaArminda do $\mathrm{N}$ as cimento Arruda é professoratitular do D epartamento de Sociologia da Universidade de São Paulo.E-mail:fs@usp.br.

\section{Abstract}

Imigrants cultural entrepreneurs in São Paulo in the 1950's

This paper discusses the relationship between immigration, industry, diversification of the elites and the creation of cultural institutions in São Paulo in the 195's, a time of intense city dynamics when it was acquiring the definite shapes of a metropolis. As a consequence of these changes, the understanding of the civilizing character imbued in cultural development became solidified, and a general homology with the modernization in course, in all spheres of society, was established. This was breeding ground for renewed cultural languages, such as 'concretism' in poetry and in the fine arts; of the theatre and film making; of architecture, design and advertising; the social sciences and urban planning; of the debates that took place in all fields. The cultural vigor of the time was gained from the dynamics of bourgeois modernity, identified with progress and compromised with the institutional building of wealthy patrons. Keywords: Immigration; Cultural entrepreneurs; Cultural institutions; São Paulo; Metropolis. 